\title{
Encartes especiais: a gestão do conflito entre publicidade e produção gráfica
}

Sergio Picciarelli Júnior*

Bacharel e licenciado em Comunicaşão Social pela Fundação Armando Álvares Penteado e especializado em Gestão de Processos Comunicacionais pela Universidade de São Paulo. Mestrando em Ciências da Comunicaşão pela Universidade de São Paulo e especialista da Área de Desenvolvimento de Novos Produtos - Editora Abril S/A, onde atua há dezoito anos. É pesquisador do grupo Comunicaşão e Trabalho da ECA-USP.

E-mail: jrsergio@hotmail.com

Resumo: Na contemporaneidade, a relação entre tempo e espaço, sociedade e trabaIho, sofreu grandes transformações. A integração dessas mudanças foi acompanhada por novos processos de homologação dos modelos de consumo e de produção. O objetivo deste artigo é demonstrar como podemos utilizar a comunicação, nesses novos modelos, para melhorar o entendimento entre departamentos e pessoas, promovendo maior informação, conhecimento e, consequentemente, contribuindo para o trabalho coletivo, ao minimizar conflitos, desentendimentos e oposição de interesses. A minha monografia apresentada na banca do curso de Gestão da Comunicação, do departamento de Comunicações e Artes da ECA/USP, sobre o tema Encartes especiais: a gestão do conflito entre publicidade e produção gráfica na mídia impressa da Editora Abril, demonstra na prática as questões citadas.

Palavras-chave: comunicação não verbal, encartes especiais, mídia impressa, revistas, Editora Abril.
Abstract: In contemporary times, the relationship between, time/space, society and work have undergone great changes. The integration of these changes was accompanied by new processes of approval of consumer and production patterns. The objective of this article is to demonstrate how we can use communication, these models, to improve the understanding between people and departments, promoting greater information, knowledge and, consequently, contributing to collective work, minimizing conflicts, discords and opposition interests. My paper was presented to a panel of Management of Communication of the ECA/USP about the theme Special Inserts managing the conflict between production and graphic advertising in printed media of Abril Publisher demonstrates in practice the questions above.

Keywords: non-verbal communication, special inserts, printed media, magazines, Editora Abril.

As transformações tecnológicas e o avanço da lógica do capital sobre a cultura passaram a exigir novas formas de persuasão incorporadas aos produtos culturais, especialmente para a publicidade. Pode-se perceber, por meio da

* Disponível em: <http:// www.eca.usp.br/comunicacaoetrabalho/>. 
comunicação \& educação • Ano XIV • Número 2 - maio/ago 2009

história das teorias da comunicação, que a abordagem do modelo comunicacional mudou de sintético e linear para outro, complexo e processual. Entre as inúmeras plataformas que sofrem essa transformação, a mídia impressa abarca amplamente a questão levantada, pois busca alternativas para manter-se competitiva diante dos demais veículos, explorando diversas formas de comunicar. Uma das opções é a criação de peças publicitárias com efeitos especiais, visando aumentar a interatividade com o leitor.

Nos últimos dez anos, as gráficas investiram e inovaram em seus parques tecnológicos, permitindo as mais variadas produções para concretizar as ideias desenvolvidas para expressão, divulgação e marketing impresso. Os efeitos são muitos e podem significar, para a maioria dos leitores, modernidade, novidade, fascínio e relação dinâmica com o mundo.

Os novos recursos disponíveis oferecem a possibilidade de relação com todos os cinco sentidos que constituem o nosso sistema de representação. Já foram produzidas peças que estimulam o tato através de relevos e vernizes, bem como aquelas com aromas cuja percepção é imediata pelo olfato e, em muitos casos, não podem ser traduzidos pela imagem ou pelo texto. A fragrância desperta diversas sensações de forma mais rápida que a imagem isolada. Até mesmo se utilizou em publicações desde fragrâncias de flores, passando pelas que estimulam o apetite, como a de panetone, e também as mais extravagantes, como a de fogueira ou a de estábulo. São usadas também formas sofisticadas de comunicação, como os casos dos pop-ups e dobraduras da embalagem no formato do produto. $\mathrm{O}$ conhecimento visual pode ilustrar e ajudar a compreender mais facilmente o que não está presente fisicamente, simulando sua presença. Outras experiências já exploraram a audição com textos ou jingles de campanhas gravados em um chip, que é acionado no momento em que o leitor abre a revista. O paladar também já foi aguçado com a veiculação de sachês com amostras de chá, suco, tempero etc.

\section{NOVAS FORMAS DE COMUNICAR NA MÍDIA IMPRESSA E OS IMPACTOS NA LINHA DE PRODUÇÃO}

Essa atual complexidade da comunicação e o uso múltiplo dos recursos comunicacionais fizeram com que a Editora Abril se preparasse, por meio da criação de uma área denominada Desenvolvimento de Novos Produtos (DNP), em 1998, para atender à demanda do mercado por produtos diferenciados. São considerados projetos especiais todos os anúncios que não são apenas propaganda de página simples - empregando, por exemplo, papéis e tintas diferentes dos utilizados em linha, novos formatos, peças com efeitos sensoriais e outros recursos. Porém, a compreensão do trabalho desenvolvido pela nova área, por parte do setor de produção gráfica, se mostrava problemática. Apesar do retorno financeiro advindo da veiculação de anúncios especiais, a área de produção responsável pela inserção dos encartes em revistas oferecia, por vezes, resistência a esse trabalho, alegando queda de eficiência em suas operações. 
Eis então o conflito entre duas áreas - publicidade e produção -, causado pela oposição de interesses resultantes do novo panorama de mercado. Surge nesse cenário a necessidade de criar um plano de intervenção, e a escolha por realizá-lo através da Gestão da Comunicação: se por um lado a área de publicidade da empresa precisa oferecer novas alternativas ao mercado, a fim de gerar mais receita - encartes com aroma, som, dobras especiais etc. -, por outro, a produção é obrigada a produzir cada vez mais num tempo menor. Acrescente-se a isso que os projetos diferenciados, não raro, implicam mudanças na linha de produção gráfica, ocasionando quedas de velocidade e desperdícios adicionais.

\section{A COMUNICAÇÃO - TEORIA E PRÁTICA}

Um dos conceitos primeiramente levados em conta dentro do estudo da comunicação é o da linguagem verbal, que se dá por meio da fala e da escrita. Bakhtin concebe a linguagem como uma criação coletiva, integrante de um diálogo cumulativo entre o eu e o outro, ou entre muitos eus e muitos outros. Considera a língua como fato social, cuja existência funda-se na necessidade de comunicação ${ }^{1}$.

Segundo Costa, as linguagens foram criadas a fim de colocar o homem em comunicação - conjuntos de signos visuais, gestuais, verbais e sonoros se organizam a partir de um grupo de regras, possibilitando a expressão através de técnicas e tecnologias de comunicação.

Chamamos tecnologia todos os equipamentos utilizados pelo ser humano na produção material ou simbólica para potencializar seu processo de criação, distribuição e consumo de bens. As tecnologias de comunicação se referem especificamente aos meios de comunicação analógicos e digitais e às telecomunicações².

Apesar de a comunicação verbal ser considerada uma competência comunicativa primária, a interação entre emissor e receptor pode ser estendida, também, por meio da integração entre as demais formas de nos comunicarmos.

$\mathrm{Na}$ década de 1930, iniciaram-se nos Estados Unidos e na Europa os primeiros estudos sobre a comunicação na sociedade. Entre os conceitos estudados no período, destacam-se as teorias do Funcionalismo e a Teoria Crítica da Escola de Frankfurt, que foram base também para os estudos teóricos na América Latina na década de 1970.

O Funcionalismo originou-se nos Estados Unidos, tendo como principais teóricos o sociólogo Paul Lazarsfeld e o cientista político Harold Lasswell. Preocupa-se em buscar a função da comunicação na sociedade, assim como a utilidade de cada elemento dentro do processo de comunicação. "Quem - Diz o quê - Em que canal - Para quem - Com que efeito?"; com estas questões, Lasswell $^{3}$ procura analisar os componentes do ato comunicativo e definir a estrutura e a função da comunicação no sistema social. De acordo com ele, qualquer processo pode ser analisado em dois ângulos: estrutural e funcional. A Escola de Frankfurt, criada na Alemanha na primeira metade do século XX,
1. BAKHTIN, Mikhail. Marxismo e filosofia da linguagem. 8. ed. São Paulo: Hucitec, 1997.

2. COSTA, Cristina. Educação, imagem e mídias. São Paulo: Cortez, 2005. p. 45.

3. LASSWELL, Harold. A estrutura e a função da comunicação na sociedade. In: COHN, Gabriel (Org.). Comunicação e indústria cultural. São Paulo: T. A. Queiroz, 1989. 
comunicação \& educação • Ano XIV • Número 2 • maio/ago 2009

4. ADORNO, Theodor W. $A$ indústria cultural. In: COHN, Gabriel (Org.). Comunicação e indústria cultural, cit.

5. BATESON, Gregory; MEAD, Margaret. Balinese Character. A Photographic Analysis (Personalidade balinesa: uma análise fotográfica). New York: New York Academy of Sciences, 1942.

6. BIRDWHISTELL, Ray, apud WINKIN, Yves. A nova comunicação. Campinas: Papirus, 1998. $p$ 40. Publicado originalmente na França em 1981 com o título La nouvelle communication.

7. Ibid., p. 13. critica o Funcionalismo e aborda, sob as óticas social e filosófica, as formas de comunicação e cultura contemporâneas, discutindo os conceitos de indústria cultural e cultura de massa - de acordo com teóricos esquerdistas como Horkheimer, Adorno, Benjamin, Marcuse e Habermas, entre outros. Para Ador$\mathrm{no}^{4}$, a indústria cultural oferece novas qualidades aos produtos, adaptando-os ao consumo de massa, formando seus consumidores e constituindo um sistema no qual tais consumidores são simplesmente objeto. O consumo de massa é a ideologia da indústria cultural: reitera, firma e força a mentalidade do consumidor, objetivando o lucro calculado, que se torna mais importante que a cultura. A demanda pré-estipulada por cultura torna o consumo homogêneo e conformistas os padrões de comportamento.

Contra o Funcionalismo norte-americano, o qual era baseado num sistema linear de transmissão de informação, diversos autores e pesquisadores desenvolveram teorias alternativas. O chamado Colégio Invisível, formado, entre outros, por Paul Watzlawick, Janet H. Beavin e Don Jackson, aponta que, quando um indivíduo fala com outro, utiliza um sem-número de regras, tanto de formação da linguagem como de utilização de um nível de linguagem apropriado a seu interlocutor, ao assunto abordado e ao lugar onde se encontram - quebrando a lógica da comunicação matemática ${ }^{5}$.

Segundo Winkin, para os autores deste colégio invisível, a comunicação é um processo social permanente que integra múltiplos modos de comportamento: a fala, o gesto, o olhar, a mímica, o espaço interindividual. Não se trata de fazer oposição entre a comunicação verbal e a comunicação não verbal, pois a comunicação é um processo integrado. Um exemplo desse processo é demonstrado por Gregory Bateson, que mostra em uma análise fotográfica, através de técnicas de descrição e de análise do comportamento não verbal combinado com o verbal, de que maneira uma criança nascida em Bali torna-se uma criança balinesa ${ }^{6}$. Observa que a comunicação verbal e a não verbal, interligadas e somadas, produzem diferentes sistemas de significantes - provando que não é apenas a linguagem verbal que pode ser entendida como transmissão de informação, ou como sistema de comunicação.

Para Ray Birdwhistell ${ }^{7}$, ainda que o indivíduo não emita comunicação, sempre participará ou irá se tornar elemento dela. Sua análise incide não sobre o conteúdo da troca, mas sobre o sistema que torna possível a troca. Esse sistema é a comunicação, que recebe prioridade conceitual sobre o sujeito que nela se insere.

Dessa maneira, através do não verbal, surge a interatividade pela comunicação em múltiplos canais, que se confirmam ou se reafirmam mutuamente. A interação é constituída da multiplicidade de modos de comunicação - como o tato, o olfato, o espaço e o tempo.

O que essa breve passagem pelas teorias da comunicação elucida é a descoberta, pelos teóricos, do caráter múltiplo e complexo da comunicação. Essa análise permite perceber que os encartes publicitários, veiculados principalmente em revistas, configuram-se como exemplo dessa multiplicidade, na medida em que invocam uma percepção plural da comunicação, mobilizando o leitor. 
Os encartes especiais trazem significações complementares ao signo verbal, como cor, textura e aroma. Dessa forma, o encarte pode ser composto por signos indiciais, criando evocações intensificadas pelo imaginário do leitor, cuja capacidade de decodificação dependerá, entre outras coisas, do ambiente social em que ele está inserido. A linguagem verbal irá ajudar na formação do pensamento, porém, os signos e as metáforas contidos nos encartes podem reforçar o entendimento das ideias construídas pelos autores da obra.

\section{A PESQUISA}

Se foi possível, dessa forma, entender a relação existente entre teoria e prática, ou seja, entre a descoberta da complexidade da comunicação e o uso profissional cada vez mais diferenciado e múltiplo dos recursos comunicacionais, o próximo passo do estudo para realizar o projeto de intervenção foi analisar os impactos desses encartes na linha de produção gráfica da empresa. Apesar de vermos crescer a demanda e a satisfação das agências de propaganda, deparávamos com a incompreensão da área de produção gráfica em relação às indispensáveis mudanças que os encartes implicam na linha de produção da revista. Existia um conflito nas relações entre criação dos encartes e a inserção deles dentro das publicações. Não havia um esclarecimento dos envolvidos a respeito da necessidade dos encartes especiais. Para tanto, fomos pesquisar áreas que pudessem fornecer argumentos para uma informação eficaz de todos os envolvidos.

$\mathrm{O}$ aumento do número de anúncios especiais era acompanhado pelo crescimento das reclamações vindas da área de produção da empresa. E-mails, reuniões e conversas de corredor apontavam os encartes especiais como responsáveis por eventuais atrasos de produção das edições.

Para entender o propósito dos protestos, podemos citar como exemplo o rendimento de uma máquina de acabamento para lombadas tipo canoa, com grampos - que pode rodar até 12 mil exemplares por hora. Ao final de cada mês, é produzido um gráfico com o desempenho de cada máquina. Esse controle costuma gerar um clima de competição entre as equipes, já que o operador será mais bem reconhecido se sua máquina produzir, ao longo do mês, uma quantidade próxima a 12 mil exemplares por hora. Os encartes especiais, em média, geram queda de velocidade de $10 \%$ - embora a área de Divisão de Novos Produtos (DNP) procure reduzir este índice, por vezes alterando formatos e estruturas dos materiais enviados pelas agências. Ainda assim, as máquinas responsáveis por rodar o encarte irão trabalhar no máximo a 10.800 exemplares por hora, o que pode resultar em mais de 20 mil exemplares a menos no relatório daquela máquina, causando desconforto aos operadores.

Esse quadro retrata a oposição de interesses dentro de um sistema de trabalho afetado pela era da globalização. As mudanças no cenário empresarial relacionam a criação de um ambiente competitivo com o aumento da produtividade e a diminuição do tempo de trabalho. 
8. Entrevista realizada em 26/01/2006.

9. TURLÃO, Felipe. TV paga recebe mais verba nos EUA. Disponível em: <http://www.portaldapropaganda.com/ midia/2006/02/0001> Acesso em: 2 maio 2006.
Nosso interesse foi pesquisar os entraves, os conflitos e a desinformação existentes ao longo do processo de produção, desde a sua criação até a inserção final nas revistas. $\mathrm{O}$ foco da pesquisa foi centrado, especificamente, na publicidade e na produção gráfica da Editora Abril, com o objetivo de detectar os problemas gerados pela falta de comunicação entre a área comercial da empresa e a área de produção, e o espaço existente dentro da empresa para o desenvolvimento de um projeto de gestão da comunicação que possa solucionar tal impasse.

A princípio, iniciamos a entrevista com os funcionários da gráfica, da área de marketing e atendimento ao leitor da Editora Abril. Após transcrição e análise dos dados, foram previstas ainda entrevistas com contatos publicitários da editora e funcionários das agências de publicidade.

\section{$1^{\text {a }}$ Análise - Justificativas para 0 investimento da empresa e da área de marketing nos encartes especiais}

Na intenção de obter dados que justificassem economicamente para anunciantes e para a gráfica a inserção dos encartes especiais nas revistas da empresa, foi realizada pesquisa com os profissionais das áreas de atendimento ao leitor e marketing da Editora Abril e com as agências de publicidade. O objetivo foi verificar se a empresa ou a agência de publicidade realizavam algum tipo de medição do retorno dos anúncios em quantidade de vendas, assim como a satisfação dos leitores baseada no número de ligações telefônicas a respeito dos encartes especiais.

O processo de coleta de dados para este estudo demonstrou que a Editora Abril não fazia, por si só, pesquisas de retorno dos encartes especiais (tecnicamente chamado de recall) junto ao público. Polyana Mazza, analista de marketing da empresa, informou que as pesquisas são efetivadas de forma pontual, apenas quando encomendadas pelos clientes ${ }^{8}$. Em um período de seis anos, foram feitas apenas duas, na área de operações especiais para revistas.

Tampouco a área de atendimento ao leitor não registrava nenhum retorno do público com relação aos anúncios especiais. De acordo com Ivair Donizete, consultor da área de informações gerenciais, o sistema de atendimento não possui códigos específicos para registrar esse tipo de manifestação dos leitores. O retorno relativo a anúncios é classificado sob o código Outros. Dessa forma, torna-se impossível verificar, por exemplo, a relação entre a veiculação dos encartes e os contatos telefônicos do público; a percepção (positiva ou negativa) dos leitores ao manusear a revista com o encarte; ou a relação percebida pelos leitores entre o anúncio e a marca da revista.

A ausência de controle detalhado da reação do público representa uma incoerência diante da importância dos encartes no total de receita publicitária da empresa. Vale lembrar que a Editora Abril detém cerca de $70 \%$ da verba publicitária do mercado brasileiro destinada a revistas. Em 2005, a verba publicitária gasta com revistas chegou a 3,2 bilhões de reais ${ }^{9}$. 
Em todas as agências de publicidade pesquisadas, constatou-se também que não há controle de retorno da veiculação dos encartes especiais. É realizado somente um acompanhamento geral da campanha, em que são computados os resultados dos anúncios de TV, rádio, internet, revistas e outros.

Mesmo sem indicadores específicos, todas as agências pesquisadas acreditam que o encarte especial cause maior impacto do que um anúncio simples. Emi Takahashi, profissional de mídia da agência Lew Lara, comenta que o leitor se identifica com esse tipo de anúncio, principalmente se for adequado ao produto. De acordo com ela, o processo de interação fará o leitor agradecer ao ser informado sobre uma causa ou mensagem que ele possa reconhecer em meio a um batalhão de informações ${ }^{10}$.

\section{$2^{a}$ Análise - Quais os conflitos gerados pela falta de comunicação entre a área comercial da empresa e a área de produção?}

Com o objetivo de confirmar as hipóteses que norteavam a execução deste trabalho, a pesquisa dentro da área de acabamento da gráfica da Editora Abril, setor que realiza a finalização das revistas, inserindo os encartes especiais, teve como foco verificar se o encarte especial realmente era visto como problema para a produção e se esta reconhecia a importância dos produtos para a empresa.

A hipótese primária da pesquisa levou em conta a existência de uma barreira, junto à equipe gráfica, para se trabalhar com o encarte diferenciado. Uma vez que a produção gráfica é medida por seu desempenho e sua velocidade, é natural que a inserção de encartes especiais não seja vista de forma positiva, já que ocasiona quedas de velocidade na produção, desperdícios adicionais e paradas de máquinas. Por outro lado, esses contratempos são cobrados do cliente dentro do orçamento de produção dos anúncios. Dessa forma, a área de produção perde em números absolutos, porém, não em valores.

Ao mesmo tempo, existia receptividade positiva por parte de algumas equipes à realização do encarte. Silvio Tassinari, gerente de produção do acabamento gráfico, comenta que muitos operadores de máquina encaram como desafio a produção de uma revista com encartes especiais, sentindo orgulho em fazê-los. Contudo, ainda era necessário mostrar a toda a equipe a importância de incrementar a produção ${ }^{11}$.

Quase todos os membros da produção, incluindo supervisores, desconheciam detalhadamente a importância desses encartes para a receita do Grupo Abril. Existia, no entanto, receptividade para a realização de uma campanha interna de conscientização a respeito, especialmente, do sistema de cobrança dos encartes. Antonio Quarelo, analista de processo, concorda com Tassinari a respeito da visão favorável de alguns profissionais aos encartes, mas considera esse um fenômeno ainda incipiente. Para a maioria dos profissionais do setor gráfico, ainda eram vistos como um complicador à produção.
10. Entrevista realizada em 9 de março de 2006.

11. Entrevista realizada no dia 10 de fevereiro de 2006. 
comunicação \& educação • Ano XIV • Número 2 - maio/ago 2009

Wesley Silva, operador de máquina, e Edmilson dos Santos, líder de máquinas, confirmaram o desconhecimento a respeito do sistema de cobrança diferenciado para os encartes especiais. Eles afirmaram que gostariam de tomar conhecimento do fluxo de informações, desde a entrada do projeto na área de publicidade até a área de faturamento, assim como dos benefícios que este tipo de projeto trazia para a empresa.

Existia o desejo, por parte das equipes, de maior envolvimento no processo de desenvolvimento dos encartes. O reconhecimento do anunciante é importante para estimular os operadores. De acordo com os entrevistados, o gerente da área costumava parabenizar o resultado final do trabalho, mas não costumava destacar a sua importância para a empresa de modo geral. Dessa forma, era preciso, ainda, fazer com que as equipes de produção se sentissem parte do projeto de realização do anúncio, merecedores também do reconhecimento do cliente.

O resultado da pesquisa demonstrou a necessidade de criar um projeto de intervenção de comunicação entre as áreas comerciais e de produção gráfica da empresa. O objetivo era minimizar os conflitos gerados pelo aumento do número de encartes especiais veiculados pelas agências e a desinformação da área de produção quanto à perda de volume nas peças produzidas, que, ao contrário do senso comum da equipe, não acarreta prejuízo de valores absolutos no faturamento. É nesse momento que a figura do gestor da comunicação deve surgir.

\section{O PROJETO DE INTERVENÇÃO COMUNICACIONAL}

Durante o decorrer do trabalho, foram identificados dois principais problemas em que o gestor da comunicação deveria atuar:

- Grande parte dos profissionais do setor de produção desconhecia a importância da inserção dos encartes especiais nas revistas da empresa e não sabia da existência de mecanismos de cobrança relativos aos desperdícios adicionais de material e à queda na velocidade na produção gráfica, que são repassados aos anunciantes, não acarretando prejuízos para a empresa.

- A área de publicidade tem pouco ou nenhum conhecimento técnico do processo de produção gráfica, porém demonstrou interesse em conhecê-lo e receber informação básica da técnica.

A partir desses problemas, quatro propostas de trabalho foram desenvolvidas para melhorar a comunicação entre as áreas de publicidade, DNP e produção gráfica. Três foram implantadas. A seguir discutiremos cada uma delas.

A primeira proposta era criar um concurso interno denominado Qual é o cheiro? O intuito era mostrar aos operadores e auxiliares de máquina qual é a importância, para a empresa, da veiculação dos encartes especiais, provocando neles as mesmas sensações que o leitor sente ao abrir a revista e ao se deparar com o anúncio. Outra intenção era destacar como é essencial a interação entre a revista e o leitor. 
Para tanto, seria utilizado o jornal interno da empresa, Fique Sabendo, para veiculação de uma campanha interativa. Em quatro edições do jornal, seriam aplicadas etiquetas com vernizes aromáticos. Cada edição teria uma um aroma diferente (a princípio, de uma fruta). Os leitores deveriam preencher o cupom identificando o aroma aplicado na etiqueta e depositá-lo em uma urna localizada em pontos estratégicos da empresa. Seriam sorteados cinco funcionários por mês, que, se respondessem corretamente, ganhariam camisetas, bolsas e relógios. Esta ação ainda não foi executada.

A segunda proposta previa a distribuição de um encarte (figura 1) para os operadores e auxiliares de máquina. $\mathrm{O}$ material explicava o processo de elaboração dos encartes especiais, desde sua criação nas agências até sua veiculação. Mostrava ainda o mecanismo de cobrança das quedas de velocidade e dos desperdícios adicionais, assim como a atuação da área de DNP, detalhando a preocupação em viabilizar materiais que evitassem o menor impacto possível na produção. O propósito era demonstrar a capacidade desse tipo de material em provocar diferentes sensações, evidenciando os benefícios que ele traz no reforço à transmissão da mensagem.

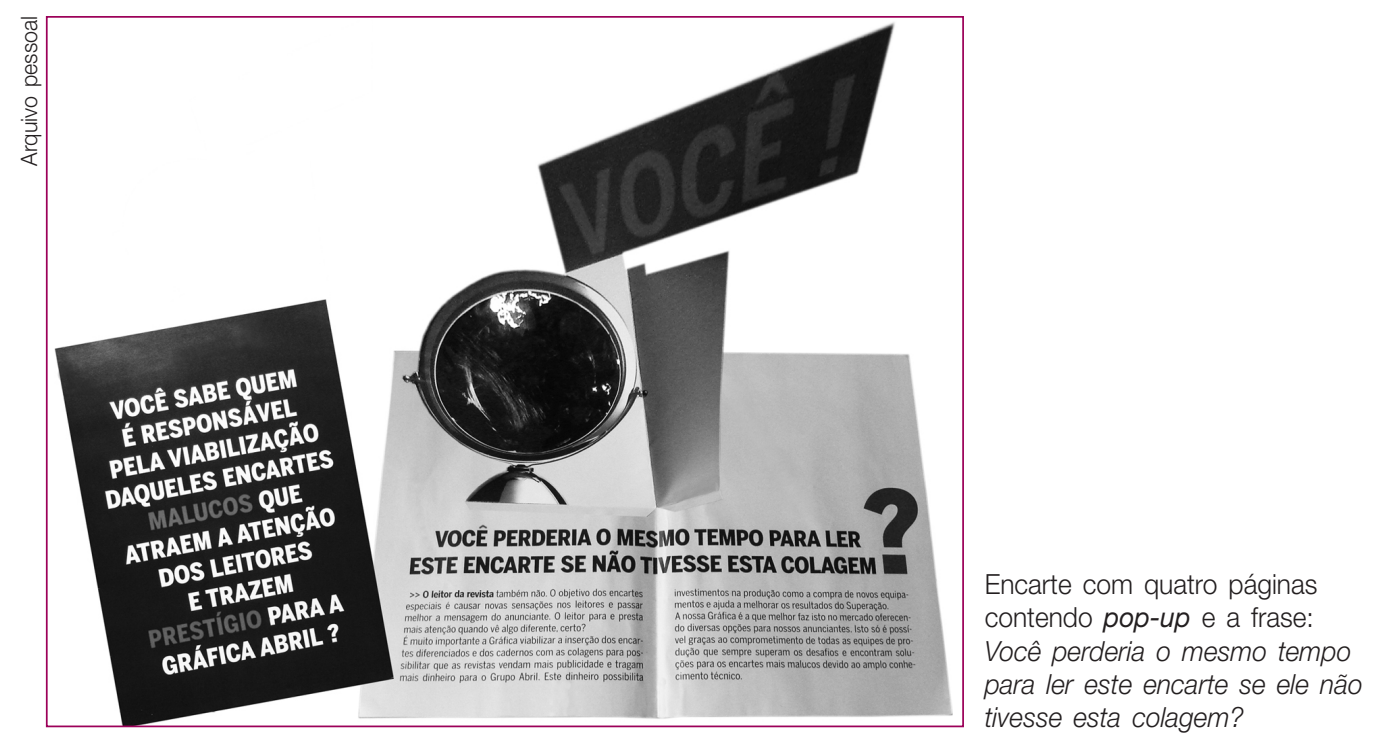

O encarte foi substituído por duas matérias veiculadas no jornal interno da gráfica, porém, com o mesmo conteúdo elaborado para o encarte. Segue matéria veiculada em agosto de 2008:

\section{Time entrosado faz encartes especiais ser um sucesso Parceria entre áreas da Gráfica deixa fluxo de anúncios diferenciados bem afinado ${ }^{12}$}

Os encartes especiais desenvolvidos para os clientes da Abril têm dado ótimos resultados, criando interatividade com o leitor e reforçando tanto o produto anunciado quanto a marca da revista, e ainda ressaltando a qualidade dos profissionais gráficos.

12. Redação: Sergio Picciarelli Júnior. Edição: Carla Werlings. 
comunicação \& educação • Ano XIV • Número 2 • maio/ago 2009

O Fique Sabendo já abordou esse tema na edição n. 58, ao falar sobre os novos formatos e sobre a Troqueladora, máquina de acabamento que auxilia na operação. "Faltava mostrar o fluxo, quem é quem nesse processo todo", comenta Sergio Picciarelli, especialista da área de Desenvolvimento de Novos Produtos - DNP - que pertence à Gráfica.

Essa operação exige que o DNP, coordenação, técnica, acabamento e impressão, e também a produção gráfica, trabalhem juntos e bem afinados. Tudo começa quando a agência de publicidade contratada pelo cliente cria o anúncio. Quando é finalizado, a área comercial da Editora Abril traz o boneco para o DNP, que faz uma pré-análise e, se necessário, encaminha para as áreas técnicas da gráfica.

O DNP e as áreas técnicas de impressão e acabamento analisam a viabilidade para a inserção do anúncio nas revistas. "Nessa hora, o apoio e a criatividade das equipes de máquina são essenciais. Sem esses profissionais seria impossível concretizar as criações", fala Sergio.

As áreas técnicas dão sugestões, fazem testes e simulações para encontrar a melhor forma de trabalhar. Toda essa preocupação justifica-se, pois a área de DNP precisa dar opções ao anunciante sem comprometer o rendimento das máquinas.

Após todos os testes e o aval das áreas técnicas, é emitido um relatório contendo queda de velocidade estimada, desperdícios adicionais, tempo extra de acerto de máquinas e outras informações necessárias para a área comercial e para a agência de publicidade.

No entanto, sempre que uma máquina roda abaixo do padrão devido ao encarte, a Abril informa ao cliente e cobra dele o suficiente para compensar a perda de produtividade. "O objetivo é inserir o encarte, mas sem perder a lucratividade da gráfica”, fala Sergio.

A terceira proposta era realizar uma apresentação aos diretores, gerentes e supervisores da Gráfica Abril sobre o fluxo de trabalho e os critérios do DNP para viabilizar as peças, assim como sobre a elaboração de orçamentos dos encartes e seu fluxo de cobrança. O objetivo era demonstrar aos líderes da empresa a preocupação da área de DNP com os impactos causados pelos encartes na área de produção, procurando oferecer ao anunciante alternativas que resultem em melhores condições de produção, em uma elaboração de orçamento coerente e em mecanismos eficazes de cobrança. Era intenção também evidenciar a importância estratégica dos encartes especiais para a área de publicidade, que precisa assegurar e expandir sua relação de clientes em um momento de acirrada concorrência entre a mídia impressa e as novas mídias.

Foram realizadas diversas reuniões com as lideranças da gráfica para expor o valor dos encartes para o Grupo Abril, explicando e definindo novas formas de planejar, viabilizar e cobrar. O resultado foi um maior envolvimento das áreas da gráfica nos projetos seguintes, melhores soluções de produção, maior apoio dos envolvidos, planejamento de produção e cobranças mais criteriosas.

A criação de um informativo foi a quarta proposta efetivada. Continha os indicadores da área de DNP, assim como uma relação dos principais encartes veiculados mensalmente pela área. $\mathrm{O}$ alvo era divulgar as peças aprovadas pelo 
DNP, mostrando por meio delas os desafios, soluções e preocupações da área, além de fazer uma rápida descrição técnica das peças - conhecimento útil em outros projetos com as mesmas características. Com essas ações esperava-se difundir, entre os contatos publicitários, conhecimentos básicos do processo de elaboração gráfica das peças, visando a futuras consultas.

$\mathrm{O}$ projeto foi um sucesso! Foram distribuídas 24 edições mensais via e-mail para diretores de publicidade, gerentes de publicidade e executivos de contas, assim como a todos os profissionais das áreas de marketing e planejamento, e de controle de processos de produção. Cada edição trazia um ou dois exemplos de encartes veiculados no mês anterior, selecionados de acordo com a dificuldade de elaboração, adaptação da criação à mensagem e interesse do público.

\section{NOTA CONCLUSIVA}

A intervenção do gestor da comunicação no processo de produção ajudou a amenizar os conflitos existentes entre as áreas de publicidade

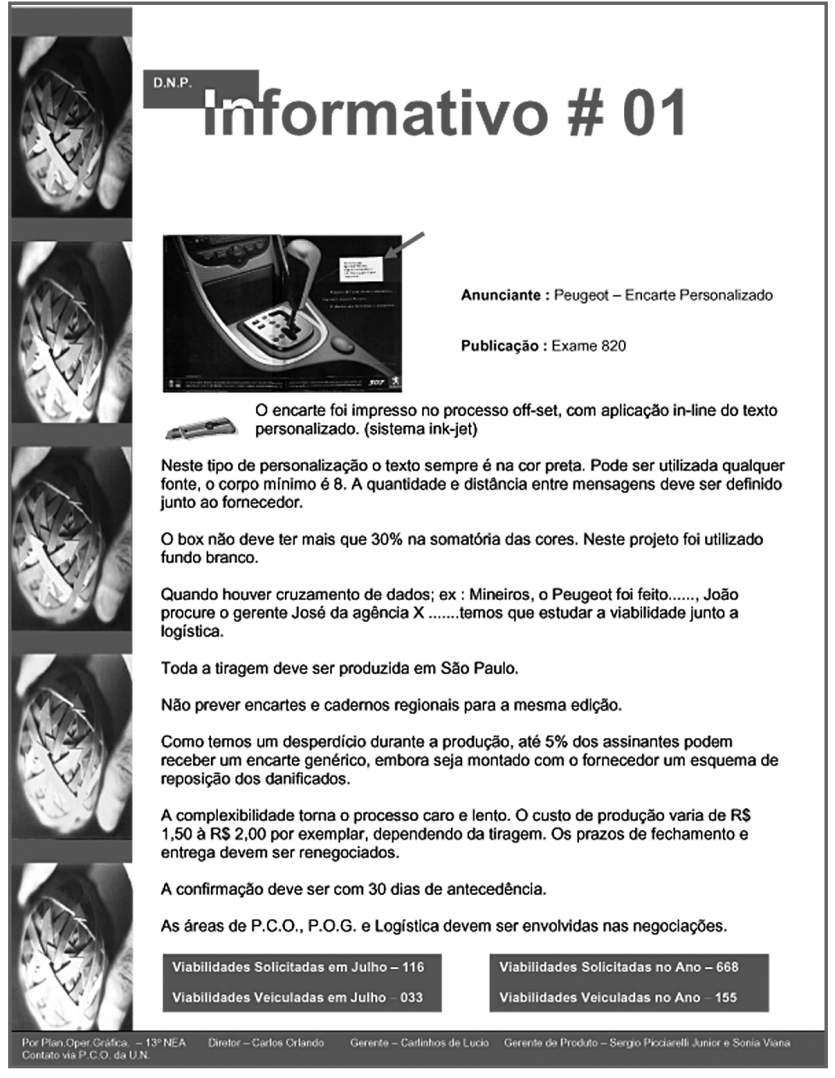

Encarte veiculado no número 1 do Informativo DNP.

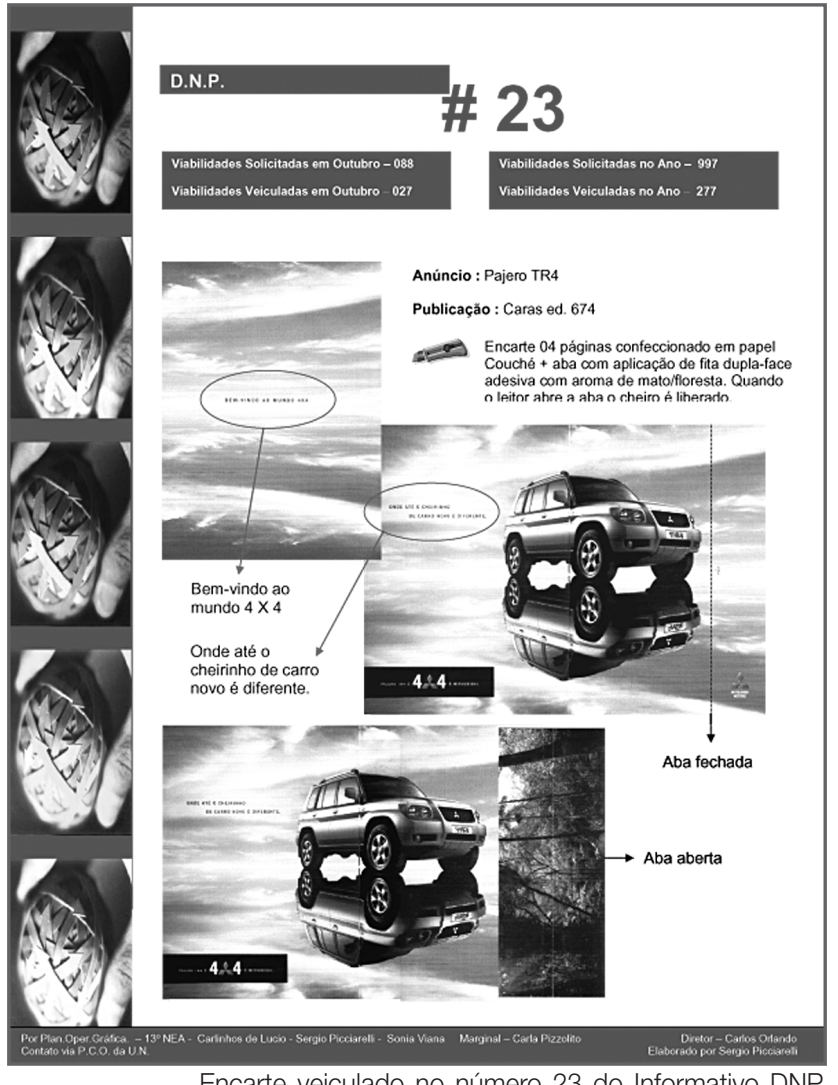

Encarte veiculado no número 23 do Informativo DNP. 
comunicação \& educação • Ano XIV • Número 2 - maio/ago 2009

e de produção. Hoje as reclamações por parte da produção são menores e as equipes estão mais comprometidas com a execução desses projetos diferenciados. Inclusive em 2008, presenciamos um movimento contrário ao padrão, quando as áreas de impressão e acabamento da gráfica tomaram a iniciativa de oferecer para a área comercial possibilidades diferenciadas de utilização de formatos e recursos dos equipamentos, com adaptações e criações concebidas pelos próprios operadores e auxiliares de máquina. Até mesmo desenvolveram um formato inovador, em que adaptaram um novo modelo de bobina de papel e uma nova engenharia de dobra na saída da máquina, veiculado na revista Casa Cláudia, edição de julho de 2008.

O problema estudado durante o curso de Gestão trouxe novas perguntas e me fez iniciar um curso de mestrado, com o objetivo de continuar a pesquisa com maior aprofundamento teórico, principalmente quanto às questões que envolvem o binômio comunicação e trabalho. Meu objetivo é compreender como as transições nos modelos produtivos, os investimentos em tecnologia e a demanda do mercado publicitário por comunicações diferenciadas e interativas impactam nos processos de produção, na profissão e na qualidade do trabalho.

\section{REFERÊNCIAS BIBLIOGRÁFICAS}

ADORNO, Theodor W. A indústria cultural. In: COHN, Gabriel (Org.). Comunicação e indústria cultural. São Paulo: T. A. Queiroz, 1989.

BATESON, Gregory; MEAD, Margaret. Balinese character: a photographic analysis (Personalidade balinesa: uma análise fotográfica). New York: New York Academy of Sciences, 1942.

BIRDWHISTELL, Ray, apud WINKIN, Yves. A nova comunicação. Campinas: Papirus, 1998. Publicado originalmente na França em 1981, com o título La nouvelle communication.

COSTA, Cristina. Educação, imagem e mídias. São Paulo: Cortez, 2005.

LASSWELL, Harold. A estrutura e a função da comunicação na sociedade. In: COHN, Gabriel (Org.). Comunicação e indústria cultural. São Paulo: T. A. Queiroz, 1989.

WINKIN, Yves. A nova comunicação. Campinas: Papirus, 1998.

Endereço eletrônico

$<$ http://www.portaldapropaganda.com/midia/2006/02/0001>. 